\title{
Mupirocin for the reduction of colonization of internal jugular cannulae-a randomized controlled trial
}

\author{
R. L. R. Hill' ${ }^{1}$ A. P. Fisher ${ }^{2}$, R. J. Ware ${ }^{2}$, S. Wilson ${ }^{2}$, and M. W. \\ Casewell ${ }^{1}$
}

Departments of ${ }^{1}$ Medical Microbiology and ${ }^{2}$ Anaesthetics and Intensive Care, King's College Hospital and School of Medicine $\mathfrak{E}^{\circ}$ Dentistry, Denmark Hill, London SE5 8RS, UK

Accepted for publication 23 February 1990

\begin{abstract}
Summary: In a prospective study, 218 cardiothoracic patients, in whom 'Abbocath- $T$ ' cannulae had been inserted preoperatively into the internal jugular vein, were randomized to receive skin preparation of the insertion site with tincture of iodine (108 controls) or tincture of iodine followed by application of sterile $2 \%$ calcium mupirocin ointment (110 test patients). Cannulae were usually removed with in $48 \mathrm{~h}$ of the operation. Patients receiving mupirocin were less likely to develop significant colonization of one or more of their cannulae as judged by Maki's criterion of a yield of $>15$ colony forming units (cfu) from a cannula segment rolled on an agar plate $(17 \%$ of mupirocin treated patients compared with $54 \%$ of the controls, $P<0.001)$. Coagulase-negative staphylococci, micrococci, or both, were the commonest isolates and were cultured from $70 \%$ of the 186 control cannulae compared with $24 \%$ of 172 cannulae inserted through mupirocin-treated skin $(P<0.001)$. A count of more than $15 \mathrm{cfu}$ was found on the tips of $25 \%$ control cannulae compared with $5 \%$ of the cannulae from mupirocin-treated patients, an effect which was independent of in-situ time $(P<0.001)$. For cannulae with colonized tips, the same species was isolated from the skin of the insertion site in $67 \%$, from the exterior of the hub in $61 \%$ and from the lumen in only $15 \%$. There were no side effects attributed to mupirocin or superinfection with resistant organisms. We conclude that in cardiothoracic patients the application of mupirocin after standard skin preparation with tincture of iodine significantly reduces the colonization of central venous cannulae by organisms derived from the skin insertion site.
\end{abstract}

Keywords: Mupirocin; jugular cannulae; skin preparation.

\section{Introduction}

Although modern medicine and surgery are often dependent on the use of intravascular cannulae, colonization of cannulae, particularly with staphylococci derived from the skin of the insertion site, may progress to local sepsis and episodes of life-threatening septicaemia (Maki, 1982; Elliot, 
1988). In a European survey of 10616 surgical patients, $4.48 \%$ of those with central venous lines acquired a bacteraemia (Nystrom et al., 1983). In the USA up to one-third of all hospital-acquired bacteraemias are derived from vascular cannulae (Maki, 1982) and in one UK hospital, infection of central venous cannulae was the commonest focus for bacteraemia with Staphylococcus aureus (Gransden, Eykyn \& Phillips, 1984).

Appropriate antimicrobial chemoprophylaxis may reduce the risk of cannula-related infection (Pezzarossi et al., 1986; Maki \& Ringer, 1987) but once an infection is established, systemic therapy may be ineffective and the cannula has to be removed (Peters \& Pulverer, 1984; Young \& Sugarman, 1985; Editorial, 1988). Application of a topical antibiotic to the skin of the insertion site has in general not been of benefit (Norden, 1969; Zinner et al., 1969 ;) although ointment containing polymyxin, neomycin and bacitracin reduced colonization of cannulae in one study by about two-thirds (Maki \& Band, 1981).

The recent introduction of mupirocin, a non-systemic antibiotic with high in-vitro anti-staphylococcal activity (Casewell \& Hill, 1985; White et al., 1985) and efficacy in the anterior nares (Casewell \& Hill, 1986; Hill, Duckworth \& Casewell, 1988) and on skin (Casewell \& Hill, 1987) prompted us to evaluate its efficacy when applied directly to the cannula insertion site.

\section{Materials and methods}

\section{Patients and skin preparation}

Between January and September 1987, 244 patients undergoing elective cardiothoracic surgery at King's College Hospital routinely had two, but occasionally one or three, internal jugular cannulae inserted percutaneously into different but adjacent puncture sites, immediately after induction of anaesthesia. Preoperatively, all patients had one to five baths and skin cleansing with 'Triclosan' (Hough, Hoseason \& Co Ltd). Routine perioperative chemoprophylaxis consisted of gentamicin $(80 \mathrm{mg})$ plus flucloxacillin $(500 \mathrm{mg})$ or erythromycin $(500 \mathrm{mg})$, both given before cannulation and then 8-hourly for $48 \mathrm{~h}$.

By means of randomization tables, patients were assigned on a weekly basis as 'test' or 'control' for skin preparation of the cannula insertion site; the microbiologists processing the specimens were unaware of the patient's allocation. Control patients received only standard skin preparation of the cannula site with tincture of iodine $(2.5 \%$ in $90 \%$ methyl alcohol). After the tincture had dried the test group received, in addition, a bolus (approximately $10 \mathrm{~mm}$ squeezed from a $15 \mathrm{~g}$ tube) of sterile $2 \%$ calcium mupirocin in a white soft paraffin base (SmithKline Beecham) applied directly to the cannulation skin site. The internal jugular vein was then cannulated through the prepared skin area with two or three 16 gauge, 5.5 inch $(12.3 \mathrm{~cm}$ ) 'Abbocath-T' (Abbott Laboratories Ltd) cannulae using a no-touch technique, but without sterile drapes, gowns or gloves. Test 
patients then received a second application of mupirocin to the puncture site. A further application of test or control treatments was made whenever cannulae were re-dressed. For all patients, the cannulation site, cannula hub and giving-set connections were covered and immobilized with 'Op-site' dressing (Smith and Nephew Ltd).

A dedicated research infection control nurse assessed cannula sites for inflammation or the presence of pus at redressing and at decannulation which was usually within $48 \mathrm{~h}$ of surgery. Other clinically evaluable data that were recorded included the indications for cardiothoracic surgery, difficulty of cannula insertion, in-situ time, antibiotic therapy and all information pertaining to infection including the results of blood cultures and other specimens taken for clinical indications.

\section{Microbiology}

The skin of the cannulation site was sampled before the application of antiseptics with a cotton-wool tipped swab moistened in nutrient broth (Oxoid CM1) which was rubbed over an area of approximately $2.5 \mathrm{~cm}^{2}$. At decannulation, the exterior of the hub and skin adjacent to the cannula and puncture site were sampled with an alginate-tipped swab (Medical Wire Co. Ltd) moistened in nutrient broth. Immediately before decannulation, residual mupirocin adjacent to the insertion site was removed with sterile gauze and an alcohol-impregnated swab. After cannula withdrawal, $5 \mathrm{ml}$ of double-strength nutrient broth from a syringe was flushed through the lumen into $5 \mathrm{ml}$ of double-strength Robertson's cooked meat broth (Oxoid CM81). The sheath was then cut aseptically from the hub and transported to the laboratory in a sterile test tube.

In the laboratory, approximately $50 \mathrm{~mm}$ of the intravenous section of the cannula tip and the intracutaneous part of the cannula were rolled back and forth five times across separate blood agar plates according to the semi-quantitative method of Maki (Maki, Weise $\&$ Saraffin, 1977) and then placed in cooked meat broths (Oxoid CM81) for enrichment culture. Lumen flush broth $(0.005 \mathrm{ml})$ was inoculated on blood agar and the remainder incubated for enrichment. Semi-quantitative cultures and those of the skin swab and lumen flush were incubated aerobically for 18-24 h. Enrichment broths were sub-cultured after 18-24 h on blood agar plates and incubated aerobically for $18-24 \mathrm{~h}$ and anaerobically for $72 \mathrm{~h}$. All incubations were at $37^{\circ} \mathrm{C}$. Isolates were identified using standard methods (Cowan, 1974), (API/Bio Merieux UK Ltd). Cannulae yielding organisms by enrichment culture only were defined as contaminated, and those yielding $>15 \mathrm{cfu}$ from semi-quantitative cultures of the intracutaneous segment or the tip were considered to be significantly colonized, in accordance with Maki's criterion (Maki, 1982). Antibiotic sensitivities were determined by a controlled disc-diffusion method using 5\% lysed horse-blood DST agar (Oxoid CM 261). Methicillin sensitivity was determined at $30^{\circ} \mathrm{C}$. Minimum inhibitory concentrations (MICs) of mupirocin were determined as previously described (Casewell \& Hill, 1985). 
Statistical analysis

The significance of differences between test and control groups was determined with the $\chi^{2}$ or Fisher's two-sided exact test for categorical data.

\section{Results}

Of the 244 patients receiving cardiothoracic surgery, 26 were excluded from the analysis: four patients in the mupirocin group and two controls died of unrelated causes before cannulae were obtained. Ten other patients in each group were excluded because no cannulae were obtained for culture. For the 218 patients studied, the features of the 110 mupirocin patients and the 108 controls were very similar (Table I). In both groups there was a predominance of males aged 50-60 yrs, most of whom underwent coronary artery bypass graft operations. A slightly higher proportion of mupirocin patients $(13 \%$ compared with $2 \%$ controls $)$ received non-standard prophylaxis, mostly because of concern about possible gentamicin- and methicillin-resistant Staphylococcus aureus (MRSA) in the hospital for about 10 days. No significant difference for the outcome of cannulae for this subgroup could be detected when compared with the patients in the mupirocin group who had received standard prophylaxis. The majority of patients in both treatment groups had two cannulae inserted into the internal jugular vein $-88 \%$ in the mupirocin group and $94 \%$ in the control group. All patients had at least one cannula cultured and complete data was obtained for 358 cannulae. The cannula-related risk factors including ease of cannulation, in-situ time, and the presence of other cannulae at decannulation, were similar for mupirocin and control groups (Table II).

Table I. Features of patients in mupirocin and control groups

\begin{tabular}{lcc}
\hline & Controls & Mupirocin \\
\hline Number studied & 108 & 110 \\
Median age (range) in yrs & $55(14-75)$ & $58(30-87)$ \\
Male (\%) & 81 & 82 \\
Operation (\%) & 79 & 80 \\
Coronary artery by-pass graft alone & 15 & 16 \\
Valve replacement & $2 \cdot 8$ & $1 \cdot 8$ \\
Both & $9 \cdot 2$ & $9 \cdot 8$ \\
Congenital anomaly correction & $0 \cdot 9$ & $2 \cdot 7$ \\
Aneurysm & & \\
Prophylaxis (\%) & 98 & 87 \\
Gentamicin + flucloxacillin/ & 2 & 13 \\
erythromycin & 0 & 3 \\
Other & 94 & 88 \\
Number of cannulae (\%) & 6 & 9 \\
One & & \\
Two & & \\
Three & & \\
\hline
\end{tabular}


Table II. Features of cannulae in mupirocin and control groups

\begin{tabular}{lcc}
\hline Cannulae cultured & Mupirocin & Controls \\
\hline Total number & 172 & 186 \\
Cannulation (\%) & 73 & 79 \\
$\quad$ Easy & 18 & 18 \\
$\quad$ Difficult & 9 & 3 \\
$\quad$ Unknown & 60 & 57 \\
In situ time $(\%)$ & 29 & 38 \\
$\quad<24 \mathrm{~h}$ & 11 & 5 \\
$2448 \mathrm{~h}$ & & 87 \\
$48-120 \mathrm{~h}$ & 64 & 1 \\
At decannulation, \% from patients: & 0 & 100 \\
$\quad$ with one other cannula in-situ & 100 & \\
with two other cannulae in-situ & & \\
receiving systemic antibiotics &
\end{tabular}

Although cannula-related bacteraemia was not detected in any of the mupirocin or control patients, and there was no significant difference in the incidence of erythema or pus at the insertion site (Table III), the application of mupirocin was consistently associated with a reduction in the proportion of patients with contamination or colonization of cannulae. As judged by positive enrichment or semiquantitative cultures, there was more than a two-fold reduction in the proportion of patients with one or more contaminated or colonized cannulae: $36 \%$ of the mupirocin-treated patients compared with $77 \%$ of the controls (Table III; $P<0.001$ ). The reduction in the proportion of patients with significant colonization of any cannula, as judged by the culture of $>15 \mathrm{cfu}$ from any cannula segment, was even greater: $18(17 \%)$ of the 110 mupirocin patients compared with $58(54 \%)$ of the 108 controls $(P<0.001)$.

Figure 1 shows that the proportion of cannulae with colonization ( $>15 \mathrm{cfu}$ ) of the intracutaneous segment or cannula tip, or with $>15 \mathrm{cfu}$ from $0.005 \mathrm{ml}$ of the cannula lumen flush, increased with in-situ time, and that patients were most likely to have positive intracutaneous segments.

Table III. Patient outcome in mupirocin and control groups

\begin{tabular}{lccc}
\hline & \multicolumn{2}{c}{ No. of patients (\%) } & \\
\cline { 2 - 3 } Patients & $\begin{array}{c}\text { Mupirocin } \\
\mathrm{n}=110\end{array}$ & $\begin{array}{c}\text { Controls } \\
\mathrm{n}=108\end{array}$ & $P$-value \\
\hline Any cannula & & & \\
$\quad$ Contaminated or colonized & $39(36)$ & $83(77)$ & $<0 \cdot 001$ \\
$\quad$ Colonized ( $>15 \mathrm{cfu})$ & $18(17)$ & $58(54)$ & $<0 \cdot 001$ \\
Erythema but no pus & $24(22)$ & $22(20)$ & NS* \\
Pus & $1(1)$ & $3(2 \cdot 7)$ & NS \\
Cannula-related bactcraemia & 0 & 0 & \\
\hline
\end{tabular}

*NS $=$ not significant. 


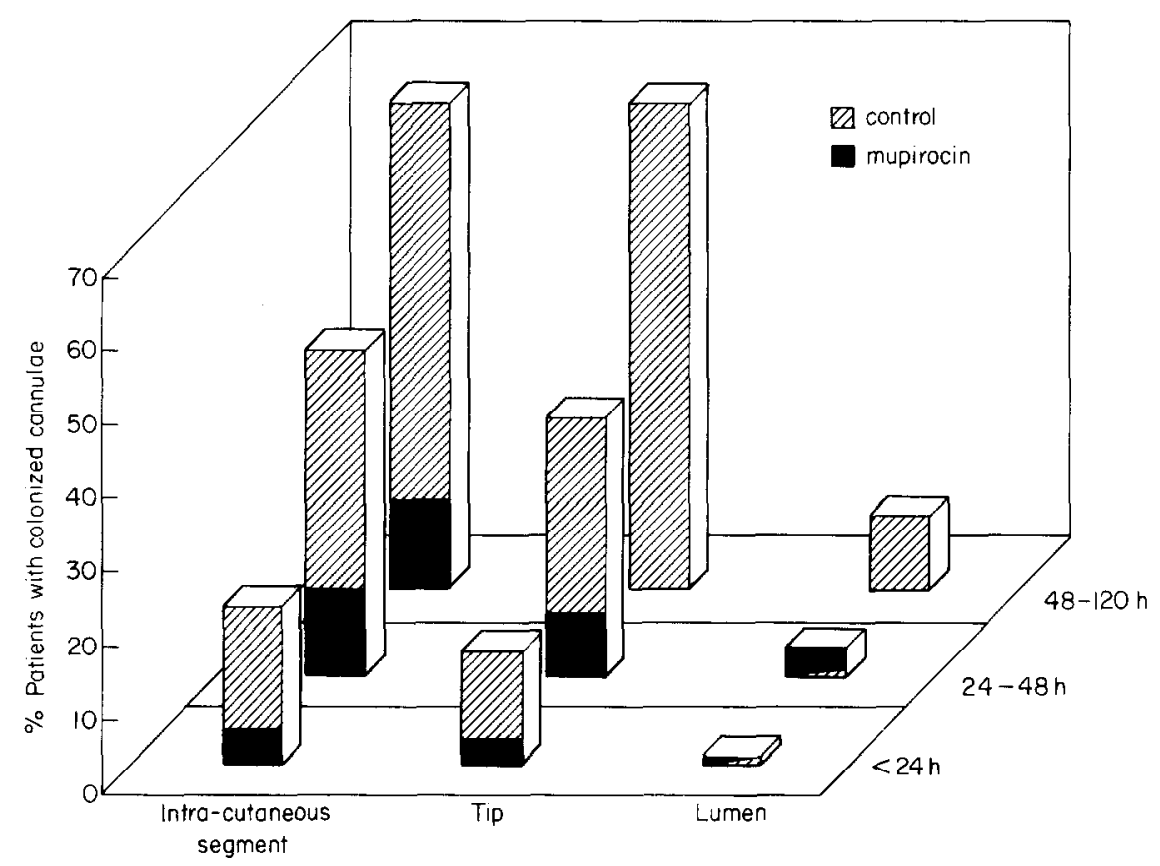

Figure 1. Effect of mupirocin on proportion of patients with one or more colonized cannulae related to in-situ time. Colonization defined as $>15 \mathrm{cfu}$ from intracutaneous segment or tip, or from $0 \cdot 005 \mathrm{ml}$ of lumen flush.

Mupirocin significantly reduced the proportion of patients with culture-positive intracutaneous segments and cannula tips and this was significant $(P<0.001)$ regardless of whether the patient had the cannula in-situ for $<24 \mathrm{~h}, 24-48 \mathrm{~h}$ or $48-120 \mathrm{~h}$. Only six patients, three in each group, had cannulae with positive luminal cultures.

All species isolated by semi-quantitative or enrichment techniques from any part of the 358 cannulae from the control and mupirocin groups are shown in Table IV. Overall, species considered to be skin flora, i.e. coagulase-negative staphylococci, micrococci, corynebacteria and Acinetobacter species accounted for more than $90 \%$ of all isolates from both mupirocin and control cannulae. More than one species was isolated from different parts of the same cannula for 24 control and 10 mupirocin canmulae. Cultures, including enrichment, of the cannula tip, intracutaneous segment, and lumen all yielded no growth significantly more often for cannulae that had been inserted through mupirocin treated skin: $64 \%$ of 172 cannulae from mupirocin patients compared with $23 \%$ of the 186 from the controls $(P<0 \cdot 001)$. If only cannulae from patients who had all their cannulae cultured were considered, the level of significant difference was unaltered as $53 \%$ of 119 cannulae from mupirocin patients yielded no growth compared to $12 \%$ of 133 control cannulae $(P<0.001)$. 
Table IV. Organisms isolated from 358 cannulae

\begin{tabular}{lcc}
\hline & \multicolumn{2}{c}{$\%$ of Cannulae } \\
\cline { 2 - 3 } Organisms & $\begin{array}{c}\text { Controls } \\
(\mathrm{n}=186)\end{array}$ & $\begin{array}{c}\text { Mupirocin } \\
(\mathrm{n}=172)\end{array}$ \\
No growth & 23 & $64^{*}$ \\
Coagulase-negative staphylococci & 62 & 19 \\
Micrococci & 8 & 5 \\
Corynebacteria & 8 & 5 \\
Ent. aglomerans & 2 & 0 \\
A. calcoaceticus & 3 & 1 \\
Staph. aureus & 2 & 2 \\
Other enterobacteriaceae & 2 & 0 \\
Ps. testosteroni & $0 \cdot 5$ & 0 \\
Moraxella sp. & $0-5$ & 0 \\
Strep. lactis & $0 \cdot 5$ & 0 \\
\hline
\end{tabular}

$* P<0 \cdot 001$

Organisms isolated by enrichment or semi-quantitative techniques from the cannula tips were usually sensitive to the prophylactic systemic antibiotics although $4 \%$ of the tip isolates were resistant to both gentamicin and flucloxacillin. All Gram-negative organisms were sensitive to gentamicin. Mupirocin-resistant coagulase-negative staphylococci, with MICs of 8 to $>128 \mathrm{mg} \mathrm{l}^{-1}$, were isolated from $10 / 84(12 \%)$ of colonized cannula tips in the control group and from $2 / 20(10 \%)$ of those from the mupirocin-treated patients; for these two mupirocin-treated patients the resistant isolates were also detected in skin swabs taken before the application of mupirocin. MICs for mupirocin-sensitive isolates of coagulase-negative staphylococci and corynebacteria ranged from $0 \cdot 015-0 \cdot 5 \mathrm{mg} \mathrm{l}^{-1}$ of mupirocin.

Table $\mathrm{V}$ shows that using Maki's criteria for significant colonization, $>15 \mathrm{cfu}$ were isolated from only $8(5 \%)$ of the tips of 172 cannulae inserted through mupirocin-treated skin insertion sites, compared with $46(25 \%)$ of the 186 controls $(P<0.001)$. The organisms isolated from significantly colonized tips corresponded most often with those from the exterior of the hub, or the skin of the insertion site. Of the 46 colonized cannula tips in the control group, indistinguishable isolates were found from the skin for $67 \%$, from the exterior of the hub for $61 \%$, and from the lumen for only $15 \%$ of cannulae. For the eight colonized cannulae from the mupirocin group, the tip isolate was identified on the skin, from the hub exterior, and from the lumen once only in three different cannulae $(P<0.001)$. Using Maki's criteria, significant colonization of cannula tips was more common with longer in-situ times but mupirocin significantly reduced the colonization for all in-situ times (Table V). None of the 19 cannulae inserted through mupirocin-treated skin that were in-situ for $48-120 \mathrm{~h}$ were colonized compared with six of the 10 controls. 
Table V. Significant colonization of cannula tips as judged by Maki's criteria according to in-situ time

\begin{tabular}{lccc}
\hline $\begin{array}{l}\text { In-situ } \\
\text { time (h) }\end{array}$ & \multicolumn{2}{c}{ Number colonized (\%) } & \\
\cline { 2 - 3 } & $\begin{array}{c}\text { Controls } \\
\mathrm{n}=186\end{array}$ & $\begin{array}{c}\text { Mupirocin } \\
\mathrm{n}=172\end{array}$ & $P$-value \\
\hline$<24$ & $105(15)$ & $103(3)$ & $<0.001$ \\
2448 & $71(34)$ & $50(10)$ & $<0.025$ \\
$>48-120$ & $10(60)$ & $19(0)$ & $<0.001$ \\
All cannulae & $186(25)$ & $172(5)$ & $<0.001$ \\
\hline
\end{tabular}

\section{Discussion}

Our results show clearly that the application of mupirocin to the skin of the cannula insertion site reduces the subsequent contamination and significant colonization of cannulae. Our patients and their cannulae were well matched in the test and control groups. All patients underwent cardiothoracic surgery, and had 'Abbocath- $T$ ' cannulae inserted preoperatively under standard conditions by the same group of anaesthetists. Previous studies have usually reported results on more heterogeneous groups of patients and cannula types (Norden, 1969; Zinner et al., 1969; Maki \& Band, 1981).

In this study, we concentrated on the earliest events in patients with central venous cannulae in the light of Maki's work which showed that contamination and established colonization of the cannula ( $>15 \mathrm{cfu}$ ) is widely accepted as a predictor of subsequent cannula-related sepsis and bacteraemia (Maki et al., 1977; Maki, 1982; Moyer, Edwards \& Farley, 1983; Elliot, 1988). As judged by enrichment culture mupirocin increased to $64 \%$ the proportion of patients who yielded sterile cannulae from $23 \%$ in the controls. More importantly, by the semi-quantitative technique only $17 \%$ of patients receiving mupirocin had any cannulae that yielded $>15 \mathrm{cfu}$, compared with $54 \%$ of the controls. The cannula tip is probably the most important site for colonization with $>15 \mathrm{cfu}$ and consideration of all 358 cannulae showed that there was a five-fold reduction of tip colonization to $5 \%$ in the mupirocin group; this effect was found regardless of $i n$-situ times up to $120 \mathrm{~h}$. We have not been able to find reductions of this magnitude in the published literature although the application of an ointment containing neomycin, bacitracin and polymyxin resulted in the colonization rate of mainly peripheral lines being reduced from $6.5 \%$ to $2 \cdot 2 \%$ compared to $3 \cdot 6 \%$ for povidone-iodine ointment (Maki \& Band, 1981). More recently Maki, by using a biodegradable collagen subcutaneous cannula cuff that released silver ions, achieved a reduction in colonization rate of central venous lines from $28.9 \%$ to $9 \cdot 1 \%$ (Maki et al., 1988).

The organisms isolated from colonized cannula tips corresponded most often to isolates from the insertion-site skin or the intracutaneous segment 
rather than to the infrequent isolates from the cannula lumen. For our cardiothoracic patients at least, this, taken with the efficacy of topical mupirocin, supports the view that it is the skin of the insertion site, rather than the lumen, that serves as the major source of organisms for colonization of the cannula tip (Bjornson et al., 1982; Snydman et al., 1982; Jakobsen, Grabe \& Damm, 1986; Cercenado et al., 1988; Conly, Grieves \& Peters, 1988; Maki, 1988). Indeed, Cooper \& Hopkins (1985) have shown by Gram staining that organisms are found on the surface of the cannula rather than in the lumen and that these organisms may reach the tip by capillary action (Cooper, Schiller \& Hopkins, 1988). In-line filtration, which could potentially prevent contaminants being introduced into the lumen via a hub, does not significantly reduce sepsis (Murphy \& Lipman, 1987). Neverthcless, the junction between the cannula and the 'giving set' may assume importance (Deital et al., 1983; Linares et al., 1985) particularly for long-term lines which have frequent 'make and break' connections, for example during parenteral nutrition (Sitges-Serra et al., $1983 \& 1984$ ) or haemodialysis (Cheesbrough, Finch \& Burden, 1986; Jakobsen et al., 1989). The presence of another cannula has been suggested as a risk factor for the development of cannula-related sepsis but its significance has not been proved (Petersen $e t$ al., 1985).

In addition to the reduction in the mupirocin group of cannula contamination and colonization with coagulase-negative staphylococci and micrococci, there were fewer cannulae yielding species of corynebacteria, Acinetobacter and Enterobacteriaceae. Although the low numbers do not reach statistical significance we wonder whether this reflects a useful effect of $2 \%\left(20000 \mathrm{mg} \mathrm{l}^{-1}\right)$ mupirocin against these species that are usually considered 'resistant' (White et al., 1985). A trial of mupirocin, applied to the insertion site of cannulae left in-situ for more than $48 \mathrm{~h}$, would indicate whether, with more prolonged use, mupirocin-resistant strains of staphylococci emerge (Baird \& Coia, 1987; Rahman, Noble \& Cookson, 1987; Smith \& Kennedy, 1988) and whether super-infection with Gram-negative bacilli, yeasts or other fungi ultimately occurs. None of these theoretical complications were found in the first few days of cannulation in our cardiothoracic surgical patients and there were no adverse local effects attributed to mupirocin.

We conclude that $2 \%$ calcium mupirocin applied to the insertion site, in addition to standard skin disinfection with tincture of iodine, significantly reduces the risk of the earliest events in the pathogenesis of cannula-related sepsis in these patients.

We thank Mr A. Forsythe and Mr J. Keates for allowing us to study their patients; the anaesthetists and intensive care and theatre nursing staff for their essential contributions; Ms Carole Vickers and Ms Angie McKenzie (SmithKline Beecham) for biometrics; Mr Richard Redhead (SmithKline Beecham) for collating data; Ms Jacqueline Mulholland for preparing the manuscript; Mrs Nergish Desai for computer graphics; the Rayne Institute for research facilities and SmithKline Beecham for providing sterile mupirocin ointment. 


\section{References}

Baird, D. \& Coia, J. (1987). Mupirocin-resistant Staphylococcus aureus. Lancet 2, 387-388.

Bjornson, H. S., Colley, R. N., Bower, R. H., Duty, V. P., Schwarz-Fulton, J. T. \& Fischer, J. E. (1982). Association between microorganism growth at the catheter insertion site and colonization of the catheter in patients receiving total parenteral nutrition. Surgery 92, 720-727.

Casewell, M. W. \& Hill, R. L. R. (1985). In-vitro activity of mupirocin ('pseudomonic acid') against clinical isolates of Staphylococcus aureus. Fournal of Antimicrobial Chemotherapy $15,523-531$.

Casewell, M.W. \& Hill, R. L. R. (1986). Elimination of nasal carriage of Staphylococcus aureus with mupirocin ('pseudomonic acid') - a controlled trial. Fournal of Antimicrobial Chemotherapy 17, 365-372.

Casewell, M. W. \& Hill, R. L. R. (1987). Mupirocin (pseudomonic acid)--a promising new topical antimicrobial agent. Fournal of Antimicrobial Chemotherapy 19, 1-5.

Cercenado, E., Ena, J., Soler, J., Romero, I., Rodriguez Creixems, M. \& Bouza, E. (1988). Origin of infection of intravascular cannulas (IVC). Proceedings of the twenty-eighth Interscience Conference on Antimicrobial Agents and Chemotherapy. Los Angeles, California: American Society for Microbiology 158 (Abstract 272).

Cheesbrough, J. S., Finch, R. G. \& Burden, R.P. (1988). A prospective study of the mechanisms of infection associated with hacmodialysis cathetcrs. Fournal of Infectious Diseases 154, 579-589.

Conly, J., Grieves, K. \& Peters, B. (1988). Pathogenesis of catheter-related infection (CRI) in central venous catheters (CVC) using gauze (G) vs transparent (TP). Proceedings of the twenty-eighth Interscience Conference on Antimicrobial Agents and Chemotherapy. Los Angeles, California: American Society for Microbiology 157 (Abstract 270).

Cooper, G. L. \& Hopkins, C. C. (1985). Rapid diagnosis of intravascular catheter-associated infection by direct Gram straining of catheter segments. New England fournal of Medicine 312, 1142-1147.

Cooper, G. L., Schiller, A. L. \& Hopkins, C. C. (1988). Possible role of capillary-associated dermal tunnel infections. Yournal of Clinical Microbiology 26, 8-12.

Cowan, S. T. (1974). Cowan $\Theta^{\circ}$ Steel's Manual for the Identification of Medical Bacteria, 2nd edn. Cambridge: Cambridge University Press.

Deitel, M., Krajden, S., Saldanha, C. F., Gregory, W. D., Fuksa, M. \& Cantwell, E. (1988). An outbreak of Staphylococcus epidermidis septicaemia. Fournal of Parenteral and Enteral Nutrition 7, 569-572.

Editorial (1988). Plastic devices: new fields for old microbes. Lancet 1, 30-31.

Elliot, T. S. J. (1988). Intravascular-device infections. Fournal of Medical Microbiology 27, 161-167.

Eykyn, S. J. (1984). Infection and intravenous catheters. Fournal of Antimicrobial Chemotherapy 14, 203-205.

Gransden, W. R., Eykyn, S. J. \& Phillips, I. (1984). Staphylococcus aureus bacteraemia: 400 episodes in St Thomas's Hospital. British Medical Fournal 288, 300-303.

Hill, R. L. R., Duckworth, G. J. \& Casewell, M. W. (1988). Elimination of nasal carriage of methicillin-resistant Staphylococcus aureus with mupirocin during a hospital outbreak. Fournal of Antimicrobial Chemotherapy 22, 377-384.

Jakobsen, C.-J. B., Grabe, N. \& Damm, M. D. (1986). A trial of povidone-iodine for prevention of contamination of intravenous cannulae. Acta Anaesthesiology Scandinavica 30, 447-449.

Jakobsen, C.-J. B., Hansen, V., Jensen, J. J. \& Grabe, M. (1989). Contamination of subclavian vein catheters: an intraluminal culture method. Fournal of Hospital Infection $13,253-260$.

Linares, J., Sitges-Serra, A., Garan, J., Perez, J. L. \& Martin, R. (1985). Pathogenesis of catheter sepsis: a prospective study with quantitative and semiquantitative cultures of catheter hub and segments. Fournal of Clinical Microbiology 21, 357-360.

Maki, D. G. (1982). Infections associated with intravascular lines. In Current Topics in Infectious Diseases No 3 (Remington, J.S. \& Swartz, M. N., Eds). London: McGraw-Hill.

Maki, D. G. (1988). Sources of infection with central venous catheters in an ICU: a prospective study. Proceedings of the twenty-eighth Interscience Conference on 
antimicrobial Agents and Chemotherapy. Los Angeles, California: American Society of Microbiology, 157 (Abstract 269).

Maki, D. G. \& Band, J. D. (1981). A comparative study of polyantibiotic and iodophor ointments in prevention of vascular catheter-related infection. American fournal of Medicine 70, 739-744.

Maki, D. G. \& Ringer, M. (1987). Evaluation of dressing regimens for prevention of infection with peripheral intravenous catheters. Fournal of the American Medical Association 258, 2396-2403.

Maki, D. G., Weise, C. E. \& Saraffin, H. W. (1977). A semiquantitative culture method for identifying intravenous catheter-related infections. New England Fournal of Medicine 296, 1395-1399.

Maki, D. G., Cobb, L., Garman, J. K., Shapiro, J. M., Ringer, M. \& Helgersen, R. B. (1988). An attachable silver-impregnated cuff for prevention of infection with central venous catheters: a prospective randomized multicenter trial. American fournal of Medicine 85, 307-314.

Moyer, M. A., Edwards, L. D. \& Farley, L. (1983). Comparative culture methods on 101 intravenous catheters: routine semiquantitative and blood cultures. Archives of Incernal Medicine 43, 66-69.

Murphy, L. M. \& Lipman, T.O. (1987). Central venous catheter care in parenteral nutrition: a review. Fournal of Parenteral and Enteral Nutrition 11, 190-201.

Norden, C. W. (1969). Application of antibiotic ointment to the site of venous catheterization-a controlled trial. Yournal of Infectious Diseases 120, 611-615.

Nystrom, B., Larsen, S. O., Dankert, J., Daschner, F., Greco, D., Gronroos, P., Jepsen, O. B., Lystad, A., Meers, P. D. \& Rotter, M. (1983). Bacteraemia in surgical patients with intravenous devices: a European multicentre incidence study. Fournal of Hospital Infection 4, 338-349.

Peters, G. \& Pulverer, G. (1984). Pathogenesis and management of Staphylococcus epidermidis 'plastic' foreign body infections. Fournal of Antimicrobial Chemotherapy 14 (Suppl. D), 67-71.

Petersen, F. B., Clift, R., Buckner, C. D., Sanders, J. E., Hickman, R. \& Meyers, J. (1985). Design and use of double lumen right atrial catheters in bone marrow transplant recipients. Acta Anaesthesiology Scandinavica 81 (Suppl.), 16-19.

Pezzarossi, H.E., Ponce de Leon, S. R., Calva, J. J., Lazo De La Vega, S. A. \& Ruiz-Palacias, G. M. (1988). High incidence of subclavian dialysis catheter-related bacteraemias. Infection Control 7, 596-599.

Rahman, M., Noble, W.C. \& Cookson, B. (1987). Mupirocin-resistant Staphylococcus aureus. Lancet 2, 387.

Sitges-Serra, A., Jaurrieta, E., Linares, J., Perez, J. L. \& Garau, J. (1983). Bacteria in total parenteral nutrition catheters: where do they come from? Lancet 1, 531.

Sitges-Serra, A., Puig, P., Linares, J., Perez, J. L., Farrero, N., Jaurrieta, E. \& Garau, J. (1984). Hub colonization as the initial step in an outbreak of catheter-related sepsis due to coagulase-negative staphylococci during parenteral nutrition. Fournal of Parenteral and Enteral Nutrition 8, 668-672.

Sitzman, J. V., Townsend, T. R., Siler, M. C., \& Bartlett, J. G. (1985). Septic and technical complications of central venous catheterization. Annals of Surgery 202, 766-770.

Smith, G. E. \& Kennedy, C. T. C. (1988). Staphylococcus aureus resistant to mupirocin. Fournal of Antimicrobial Chemotherapy 21, 141-142.

Snydman, D. R., Gorbea, H. F., Pober, B. R., Majka, J. A., Murray, S. A. \& Perry, L. K. (1982). Predictive value of surveillance skin cultures in total-parenteral-nutritionrelated infection. Lancet $2,1385-1388$.

White, A. R., Beale, A. S., Boon, R. J., Griffin, K. E., Masters, P. J. \& Sutherland, R. (1985). Antibacterial activity of mupirocin. In Bactroban (Mupirocin), (Dobson, R. L., Leyden, J. J., Noble, W. C. \& Price, J. D., Eds), pp. 19-34. London: Excerpta Medica Current Clinical Practice Series, 16.

Young, E. J. \& Sugarman, B. (1985). Introduction to prosthetic devices and their regulation in the United States. III. Infections associated with vascular catheters and other prostheses. In Infection Associated with Prosthetic Devices (Sugarman, B. \& Young, E. J., Eds), pp. 6-10. Florida: CRC Press.

Zinner, S. H., Denny-Brown, B. C., Braun, P., Burke, J. P., Toala, P. \& Kass, E. H. (1969). Risk of infection with intravenous indwelling catheters: effect of application of antibiotic ointment. Fournal of Infectious Diseases 120, 616-619. 